International Review of Research in Open and Distributed Learning Volume 21, Number 4

November - 2020

\title{
Identifying Student Perceptions of Different Instantiations of Open Pedagogy
}

John Hilton III1, Bryson Hilton², Tarah K. Ikahihifo', Reta Chaffee ${ }^{3}$, Jennifer Darrow', JoAnn Guilmett ${ }^{5}$, and David Wiley ${ }^{6}$ ${ }^{1}$ Brigham Young University, ${ }^{2}$ University of Oregon, ${ }^{3}$ Granite State College, ${ }^{4}$ Keene State College, ${ }^{5}$ Plymouth State University,

'Lumen Learning

\begin{abstract}
As the adoption of open educational resources (OER) continues to increase, instructors have started using these resources for more than simply delivering content. Open pedagogy is a term used to describe a range of instructional practices that often incorporate OER into the learning process. This study examined student perceptions of two approaches to open pedagogy-student creation of multiple-choice questions and student creation of the syllabus and corresponding course assignments. The sample included responses from 84 students at two colleges in the United States. Results showed that students who created the syllabus and assignments had a more positive experience and were more likely to enroll in a future course that implements this strategy. Those in the multiple-choice course felt that the approach was less conducive to learning than traditional learning activities. The significant differences in student feedback on two different approaches, both of which could be termed open pedagogy, indicate that more research is needed to examine the efficacy of the wide variety of approaches to open pedagogy. Moreover, the perceived efficacy of one instantiation of open pedagogy does not equal the effectiveness of open pedagogy, broadly defined.
\end{abstract}

Keywords: open educational resources, OER, open pedagogy, OER-enabled pedagogy 


\section{Introduction}

Open pedagogy is an increasingly popular choice for instructors seeking to motivate students toward deeper levels of learning, synthesis, networking, and collaboration. Instructors employing open pedagogy often use Open Educational Resources (OER) to facilitate student-directed education. Different instantiations of open pedagogy occur when instructors use OER for different elements of course material (Wiley \& Hilton, 2018). For example, Jhangiani (2017) uses OER by assigning students the task of creating multiple-choice questions. DeRosa and Robison (2017) use OER by assigning students the task of editing Wikipedia articles.

These different instantiations of open pedagogy create different experiences for students and instructors. Consider the case of Jhangiani's (2017) open pedagogy task of creating multiple-choice questions in contrast to DeRosa and Robison's (2017) open pedagogy task of editing Wikipedia articles. Hypothetically, students might be less motivated towards developing multiple-choice questions and more motivated towards editing Wikipedia articles. This potential variance in motivation could lead to widely different open pedagogy research outcomes. A lack of specific and concrete definitions in open pedagogy tasks means that research regarding open pedagogy has yet to account for differences resulting from different instantiations of forms of teaching that claim the title "open pedagogy." In this paper, we examine specific forms of open pedagogy in order to determine whether there is variance in open pedagogy instantiations and motivate future research for achieving optimal open-pedagogy outcomes. We include a literature review of open pedagogy, introduce and examine the results of two instantiations of open pedagogy, and then describe our methodology and findings.

\section{Review of Literature}

Open education research highlights "the tendency for 'open' to encompass many different interpretations and the capacity for the field to evolve accordingly" (Cronin \& MacLaren, 2018, p. 135). A review of open pedagogy in the extant literature demonstrates that some view open pedagogy as an evolving subset of the expansive definition of open educational practices (OEP) (Cronin \& MacLaren, 2018). We note that the term open pedagogy itself has shifted over time.

Earlier definitions of open pedagogy describe a classroom setting where the teacher facilitates informal discussions, thereby assisting students with co-creating the context of the class (Elliott, 1973). Mai (1978) viewed open pedagogy as an "informal classroom where children might be trusted to learn by exploring according to their own interests, instead of being bored, demeaned, and alienated” (p. 231).

In more recent years, the focus of open pedagogy has shifted towards student-centered technological approaches that emphasize collaboration outside the classroom (Hegarty, 2015; Hodgkinson-Williams \& Gray, 2009; Mackintosh, McGreal, \& Taylor, 2011). Weller (2013) found that new technologies facilitate an open pedagogy which “...places an emphasis on the network and the learner's connections within it” (p. 10). The evolving Internet-enabled definition of open pedagogy demonstrates a dramatic shift from simpler student-directed learning definitions of yesteryear to sharing and participatory definitions of today. For some, an important aspect of these collaborations is the presence of open educational resources (OER). Weller (2013) stated that open pedagogy "makes use of ... abundant, open content (such as open educational 
resources, videos, podcasts)" (p. 10). DeRosa and Robison (2017) defined open pedagogy as the use of OER "for remaking our courses so that they become not just repositories for content, but platforms for learning, collaboration and engagement with the world outside the classroom" (p. 118). Wiley (2013) suggested OER was a mandatory component of open pedagogy, stating:

This is the ultimate test of whether or not a particular approach or technique can rightly be called "open pedagogy" -is it possible without the free access and $4 \mathrm{R}$ [Wiley later added a $5^{\text {th }} \mathrm{R}$ (Wiley, 2014)] permissions characteristic of open educational resources? If the answer is yes, then you may have an effective educational practice but you don't have an instance of open pedagogy (p. 1).

This is an important point that continues to be debated. The evolving definition of open pedagogy has led researchers to question whether OER is truly a prerequisite of open pedagogy, arguing that more important issues may be democratizing educational processes (Cronin \& MacLaren, 2018; Bali, 2017). But if OER are not a part of open pedagogy, the question arises: What separates effective pedagogy from open pedagogy? In response, some, such as Wiley and Hilton (2018), have focused on a narrower term-OER-enabled pedagogies-as being "the set of teaching and learning practices that are only possible or practical in the context of the 5 R permissions which are characteristic of OER” (p. 135).

This brief overview clearly demonstrates that open pedagogy contains many different interpretations and is continuing to develop. This evolution may be a net positive, as scholars continue to explore how open pedagogy influences learning, teaching, technology, and social justice. However, as practices of open pedagogy have continued to evolve, we hypothesized that research regarding open pedagogy, broadly defined, would not be useful to practitioners given that one instantiation of open pedagogy would differ significantly from another, and that one form may be more efficacious or well received than another. The aim of the present study was to test our hypothesis by examining student perceptions of two different instantiations of open pedagogy. For the purposes of this study, we adopted a broad definition of open pedagogy, postulated by DeRosa and Robison (2017) as a platform for "learning, collaboration and engagement with the world outside the classroom" (p. 118). We note that some would likely disagree with this definition as being too expansive, while others might find it too narrow. This highlights one of the challenges of studying open pedagogy. We investigated two specific instantiations of open pedagogy by examining the perceptions of students who were either (a) in a class where they created multiple-choice questions, or (b) in a class in which they co-created the syllabus and assignments. Specifically, our research questions were as follows:

1. How do students perceive the educational value of creating multiple-choice questions relative to traditional teaching approaches?

2. How do students perceive the educational value of creating the syllabus and assignments relative to traditional teaching approaches?

3. What differences (if any) are found in student perceptions of these two approaches to open pedagogy? 


\section{Method}

Our dataset includes two instructors teaching in colleges in the United States who used open pedagogy during the spring of 2018. These instructors had been part of a seminar in open pedagogy and agreed to share their experiences in using it. Although their approaches differed significantly, both faculty members believed that they were implementing a form of open pedagogy. At the end of the semester, students in both classes were given a Qualtrics survey regarding their experiences with the open pedagogy activities in the course (Appendix). Quantitative data were reported through descriptive statistics, and the data analysis software SPSS was used to conduct chi-square tests to make cross-group comparisons on student perceptions of open pedagogy. Instructor data were collected through one-on-one interviews and e-mail correspondence. All research activities were cleared through an institutional review board.

\section{Context}

One of the instructors adopted an open textbook and used supplemental materials that she had created for the course. Her purpose in using OER was not only to save money, but more specifically to start conversations with class members about how their work might extend outside their classroom. In connection with her OER adoption, she had students create their own multiple-choice questions in lieu of doing the more traditional assignments she had used in the past. Her purpose was to have students do a renewable assignment, a renewable assignment being one that could be used in future courses to increase student learning (Hendricks, 2015; Wiley, 2013). In this case, the theory was that openly-licensed questions created by current students could benefit future students. This instructor stated that implementing her version of open pedagogy was an opportunity for her to learn new pedagogical strategies and improve her instruction. Throughout this paper, this course will be referred to as the Create MC Course $(N=43)$.

The second instructor adopted an existing open textbook that she and other faculty contributors edited. Her implementation of open pedagogy was centered around students in the class collectively creating a course syllabus for the class (within certain parameters). Students then chose their own projects for the course that had to extend outside of the classroom in some way. This was considered open pedagogy in that it put significantly more control than normal into the hands of the students who were, in a sense, co-creators of the course. Throughout this paper, this course will be referred to as the Create Assignments Course $(N=41)$.

\section{Results}

In this section, we first examine the student perceptions of the pedagogy in the Create MC Course. Subsequently, we do the same for students in the Create Assignments Course. Finally, we compare the results of the two courses.

\section{Student Perceptions of Creating Multiple-Choice Questions}

Students in the Create MC Course were asked, "Was the educational value of creating multiple-choice questions better, worse, or the same as that of traditional learning activities (e.g., writing papers, taking 
quizzes, etc.)?" Seven students (16\%) said creating multiple-choice questions was better than traditional learning activities, with eighteen (42\%) saying it was the same, and eighteen (42\%) stating it was worse. Students provided responses explaining their beliefs about the educational value of creating multiple-choice questions.

An analysis of factors prompting students to mark better centered on themes of increased understanding and depth of thought. For example, student comments included: "I had to understand what the topic is," "[I] made application of concepts more in depth," and "[It] made me think about the problem more." Students who felt creating multiple-choice questions had less educational value focused on a feeling that the assignment did not help them effectively learn. For example, one student stated, "We were ... required to regurgitate somewhat ultimately arbitrary information which didn't necessarily require critical thinking on the whole." Another student wrote, "I still had to read the entire chapter if I wanted to do good on the multiple-choice questions, therefore I still got the same information out of doing the multiple-choice questions as I would if we were to take quizzes."

Students in the Create MC Course were asked the following question: "Imagine a future course you are required to take. If two different sections of this course were offered by the same instructor during equally desirable time slots, but one section had traditional learning activities (such as writing papers and taking tests), and the other used learning activities like creating multiple-choice questions, in which section would you prefer to enroll?”

Students were more negative than positive about their desire to enroll in future courses using this type of open pedagogy activity. Eighteen students (42\%) said they would enroll in a course with traditional learning activities, twelve (28\%) said they would enroll in a course with activities like creating multiple-choice questions, and thirteen (30\%) expressed no preference.

Students selecting "I would enroll in the section with traditional learning activities" focused on themes of consistency, reliability, learning better, and earning better grades. For example, one student stated, "I learn better in those types of classes." Another student wrote, "It's what I'm used to and [excel] in."

It is interesting to note that students who said they would enroll in the sections with activities like creating multiple-choice questions also included themes of learning better and earning better grades, as well as more in-depth learning. One student stated, "It keeps you reading and keeps you understanding the content," and another wrote, "You are able to understand a concept more when you have to create questions, you have to really wrap your head around the ideas."

Students were asked to compare five different aspects of the educational efficacy of creating multiple-choice questions with traditional learning activities. Table 1 summarizes their responses. 
Table 1

Student Perceptions of Open Pedagogy With Multiple-Choice Question Creation

Outcome

Open pedagogy compared with traditional activities

\begin{tabular}{lccc} 
& More & Same & Less \\
\hline $\begin{array}{l}\text { Mastery of core } \\
\text { academic content }\end{array}$ & $11(26 \%)$ & $17(40 \%)$ & $15(35 \%)$ \\
$\begin{array}{l}\text { Skills in collaborative } \\
\text { learning }\end{array}$ & $6(14 \%)$ & $28(65 \%)$ & $9(21 \%)$ \\
$\begin{array}{l}\text { Critical thinking and } \\
\text { problem solving }\end{array}$ & $11(26 \%)$ & $28(65 \%)$ & $4(9 \%)$ \\
$\begin{array}{l}\text { Effective } \\
\text { communication }\end{array}$ & $3(7 \%)$ & $32(76 \%)$ & $7(17 \%)$ \\
$\begin{array}{l}\text { Learning how to learn } \\
\begin{array}{l}\text { Aggregate learning } \\
\text { outcomes }\end{array}\end{array}$ & $6(14 \%)$ & $32(76 \%)$ & $4(10 \%)$ \\
\hline
\end{tabular}

Note. $N=43$.

Ten students provided a free response comment on how this approach to open pedagogy helped them master core academic content more than traditional learning activities. One student wrote, "I learned the information better by having to actually think of a question to ask," and another said, "Until I could understand the topic well, I couldn't create multiple questions." In contrast, eleven students wrote about why they had lower concept mastery, focusing on a lack of learning. Two representative quotations are as follows: "I felt I was too worried about the formation of a question that I never really gave the material much thought," and "I was unable to grasp all aspects of the readings, focusing on the graded aspect of my question formatting."

When asked to explain why the activities helped them become more or less collaborative learners than in traditional learning activities, the most consistent response was that they collaborated less. Five students bluntly made statements such as, "There was nothing collaborative about [this assignment]."

Students who felt writing multiple-choice questions helped them learn to think critically or solve complex problems more than traditional learning activities wrote about depth of learning and application of knowledge. For example, one student wrote, "It made me have to apply knowledge and think more in depth about the topic." Two students wrote about why this pedagogy was less effective for critical thinking. One wrote, "I didn't think critically or solve any complex problems." 
When asked to explain why creating multiple-choice questions helped them learn to communicate more effectively than traditional learning activities, one student wrote, "Framing thoughts, organizing material." Two students provided statements about why the activities were less useful in learning to communicate effectively. One wrote, "I couldn’t really communicate anything, I was just writing questions."

With respect to learning how to learn, three students provided statements about why their outcome was more positive, centering on a theme of understanding. For example, one student wrote, "I had to understand the questions/material itself before actually creating the questions." Two students provided statements about why their outcome was less positive. The students' responses centered on a lack of focus. For example, one student wrote, "I wasn't able to focus on understanding the material as a whole. Instead I had to focus on the section I was assigned and try to make a question, often out of the most trivial aspects of its subject material, leaving me with a very loose understanding of the material."

\section{Student Perceptions of Creating the Syllabus and Assignments}

As with the students in the course with multiple-choice questions, students in the class that created the syllabus and assignments were asked, "Was the educational value of creating the syllabus and assignments better, worse, or the same as that of traditional learning activities (e.g., writing papers, taking quizzes, etc.)?" Twenty-seven students (64\%) said creating the syllabus and assignments was better, with eleven (26\%) saying it was the same, and four (10\%) stating it was worse.

The students who felt that creating a syllabus and assignments was better than traditional learning activities mentioned several factors including ownership over learning, self-pacing the course, increased engagement, development of skills such as communication and independence, the applicability of concepts, and the feeling that students were doing "less busy work" than they would have in a traditional course. The general sentiment was summarized by one student who said that the course "allowed [the students] to really take control of how [they] wanted the class to be run, and set [them] up for great success in the class."

The students who felt that creating a syllabus and assignment was the same as traditional learning activities felt that the information itself didn't change in a significant way. For example, one student wrote, "We ended up getting the same information, we were just given it in a different way."

Students who felt creating a syllabus and assignment was worse than traditional learning activities focused on factors such as lack of structure and priorities. For example, one student wrote, "Nothing is set in stone and I am unaware of what to prioritize and what the goals of the class are." This indicates that at least some students felt that a drawback of this form of open pedagogy was a lack of desired structure.

In response to the question regarding student preference in taking a future course using activities similar to creating a syllabus or assignments versus traditional activities, the majority of students in the Create Assignments Course were willing to enroll in the section using this style of open pedagogy activity. Twentyfour students (60\%) said they would enroll in a course with activities like creating a syllabus and assignments, seven (18\%) said they would enroll in a course with traditional learning activities, and nine (23\%) expressed no preference (total does not equal 100\% due to rounding). 
When asked why they would choose to enroll in a class with this type of open pedagogy activity, sixteen students responded. Their statements centered on themes of engagement, freedom, control, and ease of learning. Student comments included: "[This pedagogy] allows more freedom for the student which I like a lot more than the traditional style," "It gives me an option to structure the class how I would want to learn and be able to understand the information better," and "It's an easier way to learn and a way to choose what I want to work on."

When asked why they chose traditional activities, seven students provided responses centered on themes of preferring current norms and habits of learning. A representative comment is as follows: "I am used to [a structured class] and I feel in a course that connects to my major I can succeed more if I study and find the initiative to do good on a test rather than figure everything out on my own and be independent in my research.”

Table 2 summarizes student responses to five different aspects of the educational efficacy of creating a syllabus and assignments when compared with traditional learning activities.

Table 2

Student Perceptions of Open Pedagogy Co-Creating the Syllabus and Learning Activities

\begin{tabular}{|c|c|c|c|}
\hline \multirow{2}{*}{ Outcome } & \multicolumn{3}{|c|}{ Open pedagogy compared with traditional activities } \\
\hline & More & Same & Less \\
\hline $\begin{array}{l}\text { Mastery of core } \\
\text { academic content }\end{array}$ & $22(54 \%)$ & $16(39 \%)$ & $3(7 \%)$ \\
\hline $\begin{array}{l}\text { Skills in collaborative } \\
\text { learning }\end{array}$ & $23(56 \%)$ & $18(44 \%)$ & $0(0.00 \%)$ \\
\hline $\begin{array}{l}\text { Critical thinking and } \\
\text { problem solving }\end{array}$ & $23(56 \%)$ & $15(37 \%)$ & $3(7 \%)$ \\
\hline $\begin{array}{l}\text { Effective } \\
\text { communication }\end{array}$ & $19(46 \%)$ & $22(54 \%)$ & $0(0.00 \%)$ \\
\hline Learning how to learn & $16(39 \%)$ & $21(51 \%)$ & $4(10 \%)$ \\
\hline $\begin{array}{l}\text { Aggregate learning } \\
\text { outcomes }\end{array}$ & $103(50 \%)$ & $92(45 \%)$ & $10(5 \%)$ \\
\hline
\end{tabular}

Note. $N=41$.

Seventeen students provided comments about how the open pedagogy helped them master content more than traditional approaches. Students stated that they were more involved, connected to the content, and 
that it allowed them to "fully understand the process of [their] tasks and the reason why [they] are doing something." One student noted, "In a typical classroom, most students learn the information just so that they can do well on the test," whereas in this course, the student felt that the new knowledge was adding to a larger body of knowledge and skills.

Nineteen students explained how creating a syllabus and their own assignments made them a more collaborative learner; no students provided a response stating that it did not. Students felt that working with others on their course and assignments encouraged them to develop skills related to collaborative work and that doing so increased accountability to themselves and those around them. They also felt that it not only increased collaboration with students but between the professor and students as well. One student stated that they "work[ed] in groups a lot more than in a traditional class."

Eighteen students wrote about how the open pedagogy helped them learn to think critically or solve complex problems more than traditional learning activities. These responses discussed engagement, collaboration, and imagination. For example, one student wrote, "Engaging with students made me think more about my opinion and other students." Another student stated, "I had to come up with ways to solve real problems."

When asked to explain why creating a syllabus and learning activities helped them communicate more effectively, thirteen students wrote about how communication was vital to succeeding on the assignment. For example, one student wrote, "I had to communicate with group members, and without effective communication our product would have been crap."

With respect to how students perceived the open pedagogy helping them learn how to learn more effectively, twelve students focused on themes such as involvement, responsibility, independence, and a new style of thinking. One student wrote, "Creating a syllabus makes you responsible and forces you to be an independent learner." Another said, "It helped me think from a different angle and to look outside the box when trying to find an answer." Three students provided statements about why this approach to open pedagogy helped them learn less than traditional teaching activities. These students were concerned about the effectiveness of group participation. As one representative comment stated, "We chose how we learned which meant people could slack off in their work."

\section{Comparing Student Perceptions of Two Instantiations of Open Pedagogy}

There were strong and significant differences in how students perceived these two approaches to open pedagogy.

In response to the question, "Was the educational value of [the open pedagogy activity] better, worse, or the same as that of traditional learning activities?" students in the Create MC Course were much more likely to state that open pedagogy was worse. A chi-square test of independence was performed to examine the relation between the Create MC Course and the Create Assignments Course. The relation between these variables was significant $\left(\chi^{2}(2, N=84)=22.35, p<.001\right)$. Students in the Create Assignments Course were more likely to state the open pedagogy had higher educational value.

Similarly, students were asked this question: "Imagine a future course you are required to take. If two different sections of this course were offered by the same instructor during equally desirable time slots, but 
one section had traditional learning activities (such as writing papers and taking tests), and the other used learning activities like [the open pedagogy activity implemented in your class], in which section would you prefer to enroll?"

Students in the Create MC Course were much more likely to state they would enroll in a class with traditional learning activities. A chi-square test of independence was performed to examine the relation between the Create MC Course and the Create Assignments Course. The relation between these variables was significant $\left(\chi^{2}(2, N=83)=9.47, p<.01\right)$. Students in the Create Assignments Course were more likely to state that open pedagogy was better.

Likewise, there were significant differences in each of the five questions asking students to compare aspects of the learning with open pedagogy versus traditional activities, as described in Table 3.

Table 3

Frequencies and Chi-Square Results for Student Perception of the Efficacy of Two Open Pedagogy Methods Compared to Traditional Learning Activities

\begin{tabular}{|c|c|c|c|c|c|c|c|c|}
\hline & \multicolumn{3}{|c|}{ Create MC course $(N=43)$} & \multicolumn{3}{|c|}{$\begin{array}{l}\text { Create assignments course } \\
\qquad(N=41)\end{array}$} & \multirow{2}{*}{$\chi^{2}(2)$} & \multirow[b]{2}{*}{$p$} \\
\hline & More & Same & Less & More & Same & Less & & \\
\hline $\begin{array}{l}\text { Mastery of core } \\
\text { academic content }\end{array}$ & 11 & 17 & 15 & 22 & 16 & 3 & 11.656 & $<.01$ \\
\hline $\begin{array}{l}\text { Skills in } \\
\text { collaborative } \\
\text { learning }\end{array}$ & 6 & 28 & 9 & 23 & 18 & o & 21.104 & $<.001$ \\
\hline $\begin{array}{l}\text { Critical thinking } \\
\text { and problem } \\
\text { solving }\end{array}$ & 11 & 28 & 4 & 23 & 15 & 3 & 8.265 & .016 \\
\hline $\begin{array}{l}\text { Effective } \\
\text { communication }\end{array}$ & 3 & 32 & 7 & 19 & 22 & o & 20.479 & $<.001$ \\
\hline $\begin{array}{l}\text { Learning how to } \\
\text { learn }\end{array}$ & 6 & 32 & 4 & 16 & 21 & 4 & 6.817 & .03 \\
\hline
\end{tabular}

\section{Discussion}

The results indicate that a strong minority of students (42\%) felt that creating multiple-choice questions had less educational value than traditional learning activities. Only $16 \%$ of those who created multiplechoice questions felt this approach had more educational value than traditional learning activities. In contrast, students who engaged in creating their own syllabus and learning activities were generally 
(although not universally) positive, with nearly two-thirds reporting that it was better than traditional learning activities and an additional one-fourth stating that they had the same value.

There were statistically significant differences in how students viewed these two open pedagogy activities. Students consistently rated creating multiple-choice questions as being less conducive to learning, and stated that they would be less likely to choose a class with this approach to open pedagogy than the one focused on students creating their own syllabus and activities.

These data cannot be used to conclusively declare that creating multiple-choice questions is a poor form of open pedagogy or that students creating their own syllabus and/or learning activities is a successful one. There are several factors that we were not able to measure as part of this study that could have had significant bearing on how students perceived the specific learning activities. However, the significant differences in student attitudes towards these two approaches to open pedagogy support our hypothesis that research or rhetoric regarding open pedagogy, broadly defined, will not be particularly useful to practitioners. Had our study only focused on the Create MC Course, the results would have indicated that open pedagogy is less effective and that students dislike open pedagogy. In contrast, had we only studied the Create Assignments Course, some might have concluded that open pedagogy is an overwhelming success loved by most students.

These results suggest caution when researching and/or making claims about open pedagogy. One successful implementation of an open pedagogy approach is not enough to state that open pedagogy, broadly defined, benefits student learning. More research is needed to investigate specific aspects of open pedagogy in order to explore the relative benefits and drawbacks of different approaches. These findings suggest the importance of more specific definitions of open pedagogy so that the efficacy of a specific approach can be more critically examined. For practitioners to successfully implement open pedagogy in a way that will benefit students, specific methods need to be identified together with best practices for their implementation.

\section{Limitations}

There are several limitations in this exploratory study, and our results must be understood in that light. First, there was no attempt to control for instructor variables. The instructor who assigned students to create multiple-choice questions was attempting this approach for the first time and would likely approach it differently were she to use this technique again in the future. In contrast, the instructor who assigned students to create their own syllabus and assignments had used this pedagogy frequently in the past. Thus, what was measured in the present study may not be the efficacy of the strategy itself but, rather, the difficulty of implementing a new pedagogical approach. Similarly, it is possible that the instructor who had students create their own syllabus and assignments may have done so in a masterful way that could only be easily accomplished by a minority of faculty. Replication by a variety of instructors in different settings, as well as studying individual teachers over successive semesters would be necessary before generalizing the results of the present study. 
A second weakness is that no attempt was made to control for student differences. Nearly all the students in the Create Assignments Course were in their first semester of college versus only a third in the Create MC Course (the majority of the remainder had completed between one and four semesters). This could be a significant factor in how students responded to the various approaches to open pedagogy. Further research could remedy these limitations by systematically using different approaches to open pedagogies in similar courses and with similar student populations.

Finally, we acknowledge limitations in our survey questions. We used the terms open and traditional which could have different connotations to different people. It is possible that individual students may have a negative (or positive) perspective of traditional assignments that could have skewed their responses.

\section{Conclusion}

To our knowledge, the present study is the first of its kind to analyze specific implementations of open pedagogy and make comparisons between them. This study shows that some implementations of open pedagogy can be viewed poorly by students. We do not believe we have sufficient data to demonstrate that one approach to open pedagogy is more efficacious than another. Much more research is needed in order to determine whether specific approaches to open pedagogy are more beneficial than others. However, we do believe that broad claims such as "open pedagogy is a high-impact practice that empowers students" (“Introduction to Open Pedagogy," 2018, para. 3) currently lack empirical support.

This study has demonstrated that attempting to measure the impact of the open pedagogy, broadly defined, may be a fruitless quest. Specific approaches to open pedagogy must be examined, each in a variety of contexts with careful attention to how they are implemented. Discussions regarding open pedagogy should

focus on specific testable interventions that can be shown to improve learning. Only then will we be able to make valid claims regarding the efficacy of specific approaches to open pedagogy. 


\section{References}

Bali, M. (2017, April 21). Curation of posts on open pedagogy [Web log post]. Retrieved from https://blog.mahabali.me/whyopen/curation-of-posts-on-open-pedagogy-yearofopen

Cronin, C., \& MacLaren, I. (2018). Conceptualising OEP: A review of theoretical and empirical literature in open educational practices. Open Praxis, 1O(2), 127-143. doi: 10.5944/openpraxis.10.2.825

DeRosa, R., \& Robison, S. (2017). From OER to open pedagogy: Harnessing the power of open. In R. Jhangiani \& R. Biswas-Diener (Eds.), Open: The philosophy and practices that are revolutionizing education and science (pp. 115-124). London: Ubiquity Press. doi: $10.5334 / \mathrm{bbc} . \mathrm{i}$

Elliott, J. (1973). Is instruction outmoded? Cambridge Journal of Education, 3(3), 169-181. doi: $\underline{10.1080 / 0305764730030305}$

Hegarty, B. (2015). Attributes of open pedagogy: A model for using open educational resources. Educational Technology, 55(4), 3-13. Retrieved from https://upload.wikimedia.org/wikipedia/commons/c/ca/Ed Tech Hegarty 2015 article attrib utes_of open_pedagogy.pdf

Hendricks, C. (2015, October 29). Renewable assignments: Student work adding value to the world [Web log post]. Retrieved from http://flexible.learning.ubc.ca/news-events/renewable-assignmentsstudent-work-adding-value-to-the-world/

Hodgkinson-Williams, C., \& Gray, E. (2009). Degrees of openness: The emergence of open educational resources at the University of Cape Town. International Journal of Education and Development using ICT, 5(5), 101-116. Retrieved from https://www.learntechlib.org/p/42198/

Introduction to Open Pedagogy. (2018, September 13). Retrieved July 25, 2019 from https://libguides.uta.edu/openped

Jhangiani, R. (2017, January 12). Why have students answer questions when they can write them? [Web log post]. Retrieved from http://thatpsychprof.com/why-have-students-answer-questions-whenthey-can-write-them/

Mackintosh, W., McGreal, R., \& Taylor, J. (2011). Open education resources (OER) for assessment and credit for students project: Towards a logic model and plan for action. Retrieved from https://auspace.athabascau.ca/bitstream/handle/2149/3039/Report OACSFinalVersion.pdf?sequence $=1$ \&isAllowed $=\mathrm{y}$

Mai, R. (1978). Open education: From ideology to orthodoxy. Peabody Journal of Education, 55(3), 231237. doi:10.1080/01619567809538192

Weller, M. (2013). The battle for open - a perspective. Journal of Interactive Media in Education, 2013(3). doi: $10.5334 / 2013-15$ 
Wiley, D. (2013, October 21). What is open pedagogy? [Web log post]. Retrieved from https://opencontent.org/blog/archives/2975

Wiley, D. (2014, March 5). The access compromise and the 5th R [Web log post]. Retrieved from https://opencontent.org/blog/archives/3221

Wiley, D., \& Hilton, J. (2018). Defining OER-enabled pedagogy. The International Review of Research in Open and Distributed Learning, 19(4), 133-147. doi: 10.19173/irrodl.v19i4.3601 


\section{Appendix}

\section{Survey Taken by Students}

The following are general questions related to you and your courses at the college.

Q1 How many terms/semesters have you completed in college?

O Less than 1 (1)

O 1 -2 (2)

O $3-4(3)$

O $5-6(4)$

O $7-8(5)$

O $9-10(6)$

O More than 10 (7)

Q2 What is your cumulative college Grade Point Average (GPA) on a 4.0 scale?

O $0.0-1.4(1)$

O $1.5-2.0(2)$

O $2.1-2.5(3)$

O $2.6-3.0(4)$

O $3.1-3.5(5)$

O $3.6-4.0(6)$

This is my first term (7)

O I don't know

Q3 In general, how often do you rent the required course materials for the courses you take?

O Never (1)

O Rarely (2)

O About Half the Time (3)

O Often (4)

O Always (5)

Q4 In general, how often do you purchase the required course materials for the courses you take?

O Never (1)

O Rarely (2)

O About Half the Time (3)

O Often (4)

O Always (5)

Q5 Have you ever not purchased course materials for a class because of the cost of the course materials?
a. No
b. Yes 
Q6 (If yes to 5) Do you think that not purchasing the course materials influenced your grade in the course in a negative way?
a. $\quad$ No
b. Yes

Q7 (If yes to 5) Has not purchasing course materials contributed to your decision to drop a course?
a. No
b. Yes

Q8 (If yes to 5) Has not purchasing course materials ever caused you to fail or withdraw from a course?
a. No
b. Yes

Q9 Have you ever delayed purchasing course materials for a class because of the cost of the course materials?
a. No
b. Yes

Q10 (if yes to 9) Do you think that delaying purchasing the course materials influenced your grade in a negative way?
a. No
b. Yes

Q11 Have you ever registered for fewer courses because of course materials costs?
a. $\quad$ No
b. Yes

Q12 Have you ever not registered for a specific section of a course because of course materials costs?
a. $\quad$ No
b. Yes

Your instructor included the following open pedagogy activity in your course: [insert open pedagogy phrase]. The following questions relate to your participation in the course's [insert open pedagogy phrase] in which [insert description of open pedagogy used]. In the questions below this is referred to as "the course's [insert open pedagogy phrase].”

Q13 Have you ever completed an assignment similar to participating in the course's [insert open pedagogy phrase] in another class?

Q14 Was the educational value of participating in the course's [insert open pedagogy phrase] BETTER, WORSE, or the SAME AS that of traditional learning activities (e.g., writing papers, taking quizzes, etc.).
a. Better
b. Same
c. Worse

14.1 [if Better in 14] in what ways was it better?

14.2 [if Same in 14] in what ways was it the same?

14.3 [if Worse in 14] in what ways was it worse? 
Q15 When your instructor asked you to participate in the course's [insert open pedagogy phrase], did this change your opinion of your instructor?
a. Yes
b. No

Q16 [if yes to 15] How did your perception of your instructor change?

Q17 Suppose that certain types of learning activities lead to certain learning outcomes. For example, reviewing flash cards might lead to memorizing facts. What types of learning outcomes do you think are the result of participating in the course's [insert open pedagogy phrase]?

Q18 Imagine a future course you are required to take. If two different sections of this course were offered by the same instructor during equally desirable time slots, but one section had traditional learning activities (such as writing papers and taking tests), and the other used learning activities like participating in the course's [insert open pedagogy phrase], in which section would you prefer to enroll?

- I would enroll in the section with TRADITIONAL LEARNING ACTIVITIES

- I would enroll in the section with ACTIVITIES LIKE PARTICIPATING IN AN [insert open pedagogy phrase]

- I would have no preference

Q18.1 [if TRADITIONAL] Why would you choose a class with traditional learning activities?

Q18.2 [if ACTIVITIES LIKE PARTICIPATING IN AN [insert open pedagogy phrase]] Why would you choose a class with activities like participating in [insert open pedagogy phrase]?

Q19 In this course, did you create any resources that were shared online or intended for reuse by others in the future?

Q 19.1 (if yes to Q19) Did you use an open license, like a Creative Commons license, to license any of the resources you created for this course?

Yes

No

Q 19.2 (if yes to Q19) Did you feel pressured to license your work in a certain way?

Yes

No

Q 19.3 (if yes to Q19.2) Please share how you felt pressured to license your work and how this impacted you.

Q20 How did participating in the course's [insert open pedagogy phrase] help you master core academic content, compared to the way engaging in traditional learning activities (like writing essays or taking quizzes) would have?

- Participating in the course's [insert open pedagogy phrase] helped me master MORE core academic content than traditional learning activities would have 
- Participating in the course's [insert open pedagogy phrase] helped me master THE SAME AMOUNT of core academic content as traditional learning activities would have

- Participating in the course's [insert open pedagogy phrase] helped me master LESS core academic content than traditional learning activities would have

20.1 [if more] Why did participating in the course's [insert open pedagogy phrase] help you master MORE core academic content than traditional learning activities would have?

20.2 [if less] Why did participating in the course's [insert open pedagogy phrase] help you master LESS core academic content than traditional learning activities would have?

Q21 Reflect on the collaborative nature of the [insert open pedagogy phrase]. Select one of the following:

- Participating in the course's [insert open pedagogy phrase] helped me become a MORE collaborative learner than traditional learning activities would have

- Participating in the course's [insert open pedagogy phrase] helped me collaborate with other learners THE SAME AMOUNT that traditional learning activities would have

- Participating in the course's [insert open pedagogy phrase] helped me become a LESS collaborative learner than traditional learning activities would have

21.1 [if more] Why did participating in the course's [insert open pedagogy phrase] help you become a MORE collaborative learner than traditional learning activities would have? 21.2 [if less] Why did participating in the course's [insert open pedagogy phrase] help you become a LESS collaborative learner than traditional learning activities would have

Q22 Reflect on how the [insert open pedagogy phrase] helped you learn to think critically or solve complex problems. Select one of the following:

- Participating in the course's [insert open pedagogy phrase] helped me become a MORE critical thinker and better problem solver than traditional learning activities would have

- Participating in the course's [insert open pedagogy phrase] helped my critical thinking or problem solving skills THE SAME AMOUNT that traditional learning activities would have

- Participating in the course's [insert open pedagogy phrase] helped me become a LESS critical thinker and worse problem solver than traditional learning activities would have 22.1 [if more] Why did participating in the course's [insert open pedagogy phrase] help you learn to think critically or solve complex problems MORE than traditional learning activities would have? 22.2 [if less] Why did participating in the course's [insert open pedagogy phrase] help you learn to think critically or solve complex problems LESS than traditional learning activities would have?

Q23 Reflect on how the [insert open pedagogy phrase] helped you learn to communicate effectively. Select one of the following:

- Participating in the course's [insert open pedagogy phrase] helped me become a MORE effective communicator than traditional learning activities would have

- Participating in the course's [insert open pedagogy phrase] helped my critical thinking or problem solving skills THE SAME AMOUNT that traditional learning activities would have

- Participating in the course's [insert open pedagogy phrase] helped me become a LESS critical thinker and worse problem solver than traditional learning activities would have

23.1 [if more] Why did participating in the course's [insert open pedagogy phrase] help you become a MORE effective communicator than traditional learning activities would have? 
23.2 [if less] Why did participating in the course's [insert open pedagogy phrase] help you become a LESS effective communicator than traditional learning activities would have?

Q24 Reflect on how the [insert open pedagogy phrase] helped you learn more effectively. Select one of the following:

- Participating in the course's [insert open pedagogy phrase] helped me learn MORE effectively than traditional learning activities would have

- Participating in the course's [insert open pedagogy phrase] helped me learn THE SAME AMOUNT that traditional learning activities would have

- Participating in the course's [insert open pedagogy phrase] helped me learn LESS effectively than traditional learning activities would have

24.1 [if more] Why did participating in the course's [insert open pedagogy phrase] help you learn MORE effectively than traditional learning activities would have?

24.2 [if less] Why did participating in the course's [insert open pedagogy phrase] help you learn LESS effectively than traditional learning activities would have?

\section{Athabasca} University

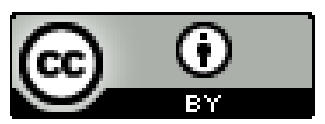

